\title{
Investigaciones acerca del Complejo Chuqui ${ }^{1}$
}

\author{
Robert Bruce Grove ${ }^{1}$
}

El Complejo Chuqui, tal como lo describe Lanning (1970 y 1973), consiste principalmente en pequeñas herramientas con trabajo unilateral y ángulos de borde relativamente abruptos. Se dice que las herramientas fueron hechas, en general, sobre trozos de roca de forma tubular. También se dice que están presentes algunos buriles hechos sobre nódulos, y que las principales materias primas de los artefactos son una toba altamente silicificada y una piedra caliza silicificada.

Todos, excepto uno de los sitios atribuidos al Complejo Chuqui, se ubican en el salar de Talabre (Figuras 1 y 2). La excepción es RAnL-220, que yace al sur del río Loa cerca de la confluencia de los ríos Loa y Salado. Como no he tenido acceso a la documentación del survey de RAnL-220 ni a los materiales, no lo discutiré en este artículo. Los sitios del salar de Talabre yacen en línea, a lo largo de unos $2.5 \mathrm{~km}$, con un promedio de unos $60 \mathrm{~m}$ de ancho (Figura 2). Los sitios van en línea recta entre Calama y Chiu Chiu. Por lo menos una de las materias primas de los supuestos artefactos Chuqui está presente en forma natural en cada sitio del complejo.

Sobre la base de comparaciones tecnológicas y morfológicas Lanning ha situado el Complejo Chuqui en su tradición de bordes retocados, la que él cree puede datarse hacia 16000 o 17000 AC (Lanning 1970). También especifica que algunos elementos de su postulada tradición de buriles, datada hacia los 14000 AC, en la cueva Pikimachay en Perú, también están presentes en el Complejo Chuqui.

Los investigadores de la estación de campo de la Universidad de Columbia hicieron recolecciones superficiales en los sitios de Chuqui en 1966, pero las áreas de las recolecciones no fueron marcadas. De

1 Traducción de Cora Moragas, Departamento de Arqueología, Facultad de Ciencias Sociales, Universidad del Norte. esta manera, la distribución espacial y tipológica del material de Chuqui de los sitios fue perturbada, por lo tanto la validez de cualquier conclusión tomada de mi recolección no es tan certera como debió haber sido. Mi trabajo involucró una excavación limitada y recolección superficial cuidadosamente controlada en cuatro sitios de Chuqui. Estos sitios se escogieron porque estaban dispersos en el rango temporal del Complejo Chuqui, como lo indicaba una seriación de una parte de las colecciones de 1966. También se hicieron recolecciones superficiales controladas en un sitio cercano, Talabre 3, con propósitos comparativos.

En el sitio RAnL-6, que yace en el borde de la terraza-alta sobre el salar de Talabre, y sobre un sendero, se realizó primero un mapeo (Figura 3). Para lograrlo revisé la extensión de la dispersión del material foráneo dentro de los límites del sitio. Esta resultó ser un área de mayor dimensión de lo que se indicaba en las notas originales del survey del sitio $6 \mathrm{~A}$. Como la parte baja de $6 \mathrm{~B}$ es simplemente material de acarreo de la colina, y continúa con una dispersión muy leve, casi hasta el sitio RAnL-22, he delimitado arbitrariamente el sitio 6B en el sendero que atraviesa la base de la colina.

Cuando el mapeo estuvo terminado, dividí el sitio 6A en 451 cuadrantes de $5 \mathrm{~m}$ por lado (Figura 4). Cada cuadrante de número impar se apareaba con el siguiente cuadrante par. Al azar (cara o sello) se decidió en cuál de ambos cuadrantes se recolectarían solamente los artefactos y en cuál se recolectarían tanto los artefactos como el material foráneo. De esta manera la mitad de la superficie del sitio 6A fue recolectada con un criterio y la otra mitad con el otro. También se excavaron dos cuadrantes en 6A. Como la colina de 6B indicaba que no valdría la pena recolectar en esa área para datos de distribución, solamente hice la recolección de superficie en cinco cuadrantes de $5 \mathrm{~m}^{2}$ en una de las áreas con más concentración. 


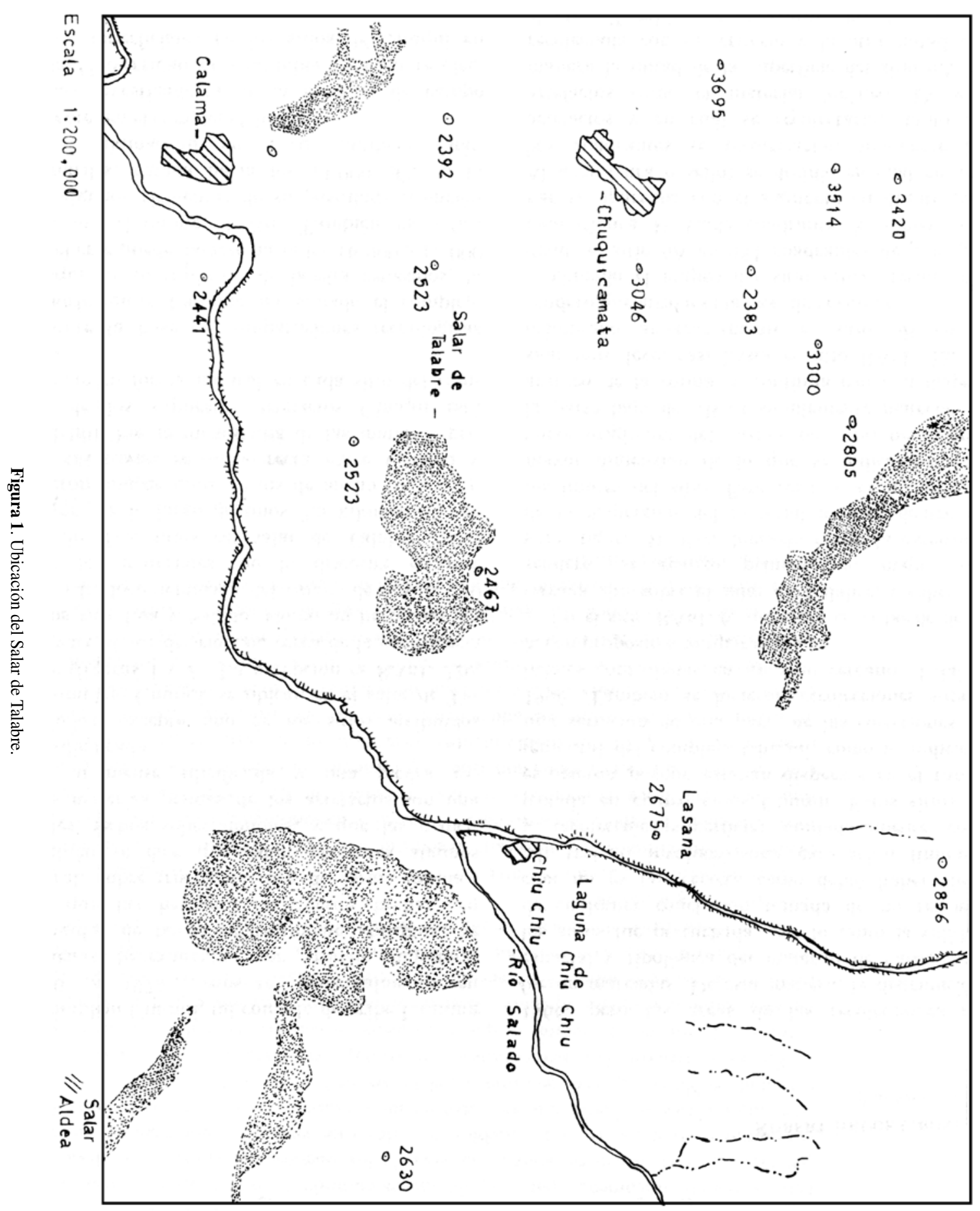




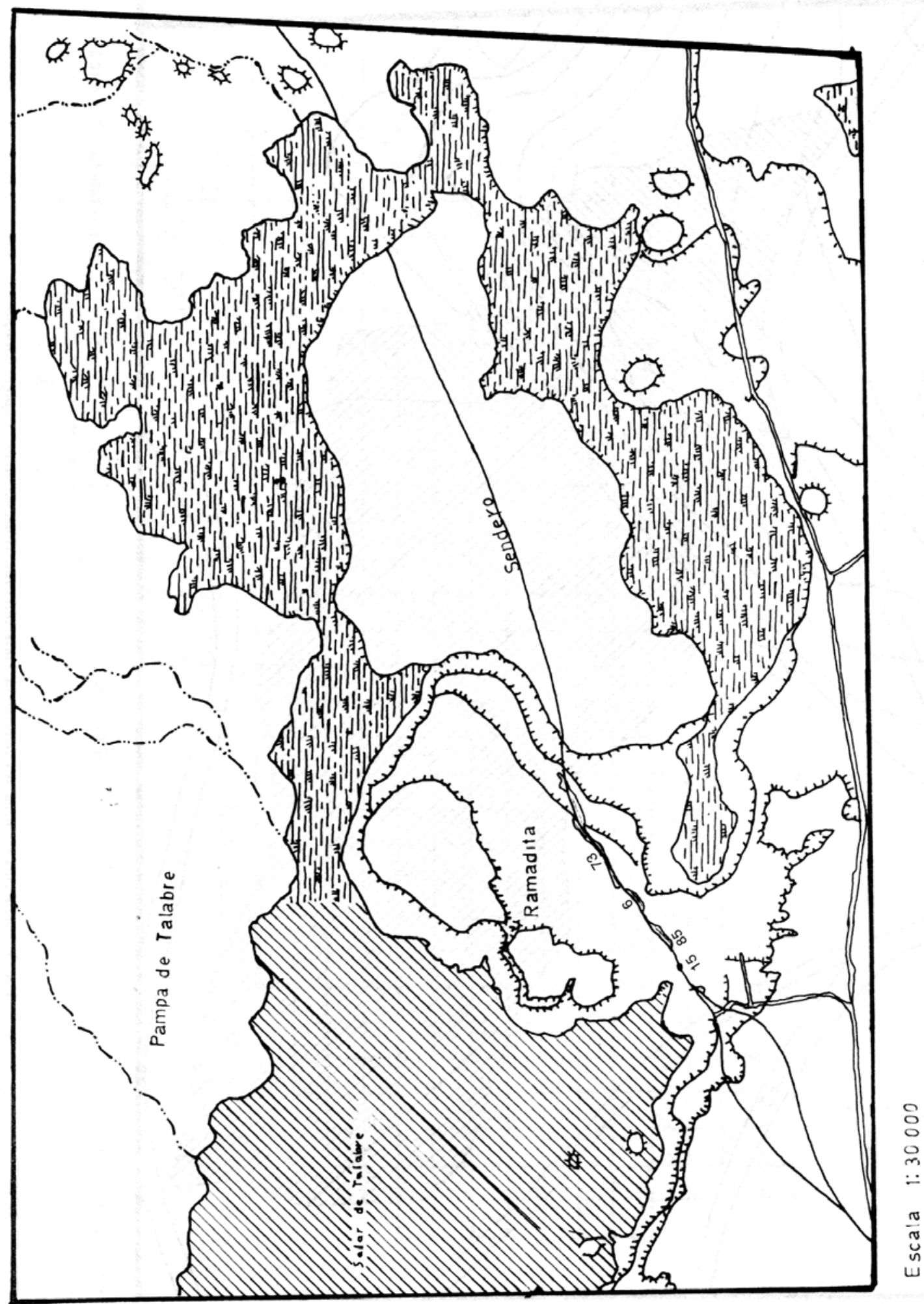




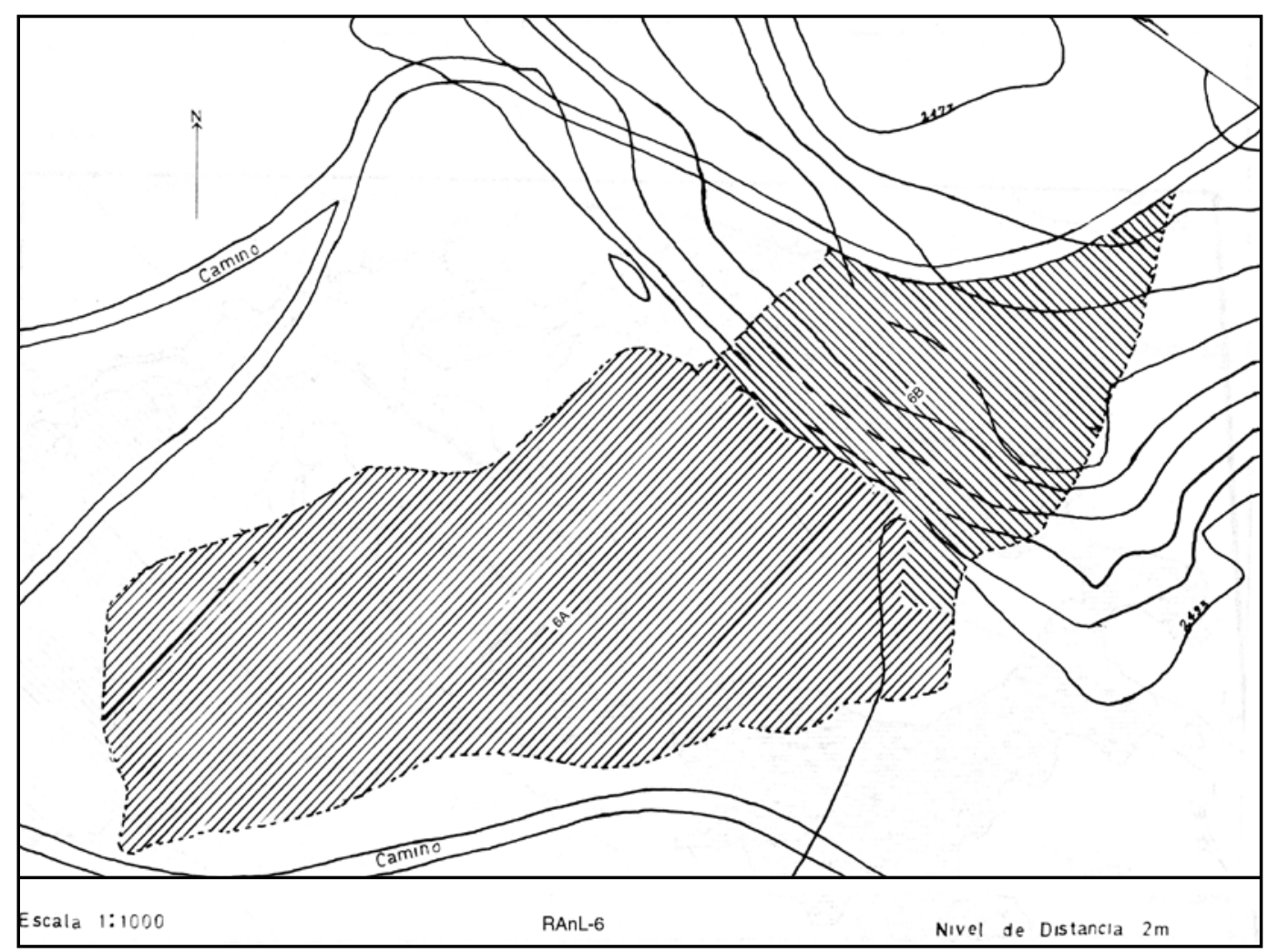

Figura 3. Sitio RAnL-6: Area de colección de materiales líticos del llamdo Complejo Chuqui.

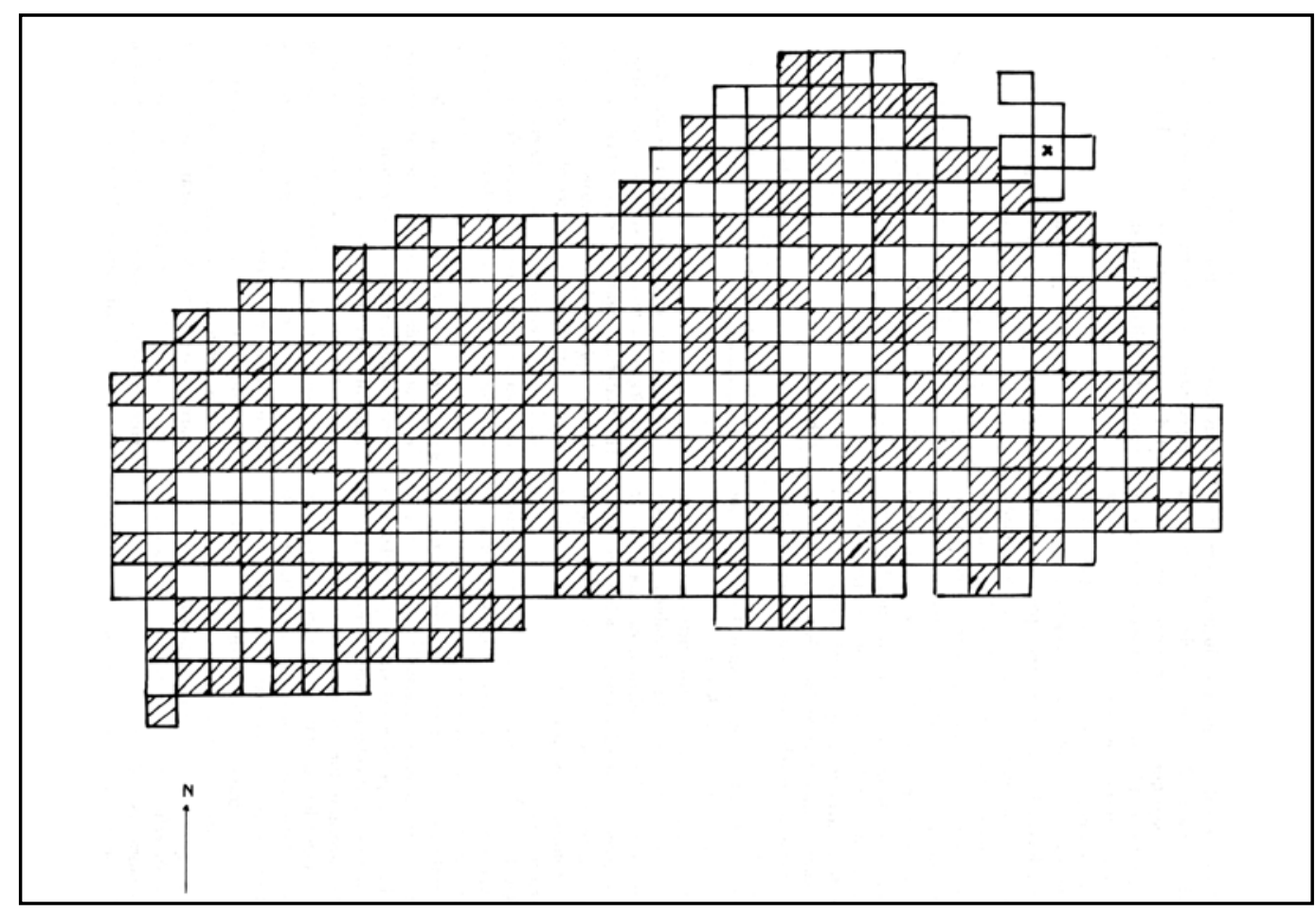

Figura 4. RAnL-6: Recolección de artefactos. Las cuadrículas sombreadas sirvieron de control de la industria línea. 
El sitio RAnL-22, que yace justo al noreste de RAnL-6 (Figura 2) y en una elevación de unos 25 m más bajo que 6A, fue el primer sitio trabajado en 1969. El sitio fue mapeado y luego se trazó una trinchera de 10 m x 4 m en el área de mayor concentración de materiales. Las líneas que formaban los lados de la trinchera se extendieron, logrando formar ocho áreas para una total recolección de superficie. La trinchera misma fue dividida en cuadrantes de $2 \mathrm{~m} \times 2 \mathrm{~m}$. Algunos cuadrantes se excavaron sólo a través de la capa suelta de arena superficial. Todos los demás cuadrantes, excepto el 1, se excavaron hasta la superficie de una capa de sal dura y laminada. En el cuadrante 1 la excavación se hizo profundizando a través de la capa de sal, y llegando a un material más blando bajo ésta. La capa de sal y todos los niveles bajo ésta fueron culturalmente estériles.

El sitio RAnL-75 es el sitio Talabre 3, que yace justo al norte de RAnL-73. Se trazaron cuatro cuadrantes de $4 \mathrm{~m}$, y se hizo una recolección completa. También se recogieron tres talleres individuales ubicados en los márgenes inmediatamente sobre el sitio. Estos materiales fueron analizados con propósitos comparativos pero no se ilustran ni se describen aquí.

RAnL-85, el último sitio donde se realizaron excavaciones, yace a unos pocos cientos de metros al oeste de los sitios 73 y 75 (Figura 2). Se realizaron los mismos procedimientos de mapeo y recolección superficial que en el sitio 73. La superficie total del sitio y parte del área que lo rodea se dividió en cuadrantes de $4 \mathrm{~m}$. Cada cuadrante fue numerado y se tomó muestra de todos los cuadrantes con números impares. Para reducir este muestreo tipo "tablero de ajedrez" a un tamaño más manejable, se seleccionaron cuadrantes de cada tipo de superficie, para obtener una muestra proporcional y correcta que cubría aproximadamente $20 \%$ de la superficie del sitio. Además, se excavaron dos cuadrantes de $2 \mathrm{~m}$.

No se recolectó más material en los sitios Chuqui, pero sí se colectaron especímenes de lasqueo natural del mismo tipo de materia prima de los especímenes de Chuqui en áreas no culturales. También se obtuvieron ejemplares con desgaste natural en varios tipos de rocas en otras áreas a lo largo de los senderos que cruzan los sitios (Figura 5).

El número de especímenes recuperados fue muy bajo. Sin embargo, una gran parte de los especímenes son de tipos que se ubican en períodos relativamente recientes. La Tabla 1 resume los hallazgos por sitio.

\begin{tabular}{|l|r|r|r|}
\hline \multicolumn{1}{|c|}{ Sitio } & Lítico & Cerámica & Total \\
\hline 6A & 113 & 1301 & 1414 \\
\hline $6 \mathrm{~B}$ & 9 & 104 & 113 \\
\hline 22 & 8 & 226 & 234 \\
\hline 73 & 17 & 7 & 24 \\
\hline 85 & 47 & 0 & 47 \\
\hline $85 \mathrm{~B}$ & 2 & 0 & 2 \\
\hline Total & 196 & 1638 & 1834 \\
\hline
\end{tabular}

Tabla 1. Número de especímenes registrados por sitio. En la mayoría de los casos, los tiestos son pequeños y muy erosionados.

En cada sitio también apareció algo de material orgánico, tanto en superficie como bajo ella. El material orgánico de superficie consistía en huesos (principalmente de caballo y burro), fragmentos de pezuñas, estiércol (principalmente de llama), ramas $\mathrm{y}$ algunos materiales acarreados por el viento, como pedazos de papel. Inmediatamente bajo la superficie se encontraron semillas de algarrobo y chañar, pelo y estiércol de llama, y en el sitio 22, cuerdas de lana. La explicación de los hallazgos de este tipo de material orgánico bajo la superficie es que probablemente fueron tirados por los viajeros que pasaban por los senderos, y enterrados por las patas de los animales. Esta explicación se sostiene por el hecho de que tal material orgánico puede encontrarse rebuscando a lo largo de cualquier camino, pero nunca lejos de ellos.

Los senderos que cruzan el sitio (Figura 6) parecen ser parte de un gran sistema de rutas en el área. Los de particular importancia van entre Calama $v$ Chiu Chiu, en una distancia de cerca de $30 \mathrm{~km}$. La evidencia cerámica en los sitios Chuqui y en todos los otros senderos indican que estas rutas han estado en uso por lo menos hace 2000 años. Esta cifra está basada en la única fecha radiocarbónica del cuadrante J del sitio 73 (Lanning, com. pers.).

Los senderos están bien desarrollados, llegando a tener en algunos lugares hasta $100 \mathrm{~m}$ de ancho. En otros lugares donde el ancho ha sido restringido por obstáculos naturales, las rutas individuales tienen más de $30 \mathrm{~cm}$ de profundidad. En muchos lugares los senderos se usaron tanto para animales de carga como para vehículos con ruedas, mientras que en 


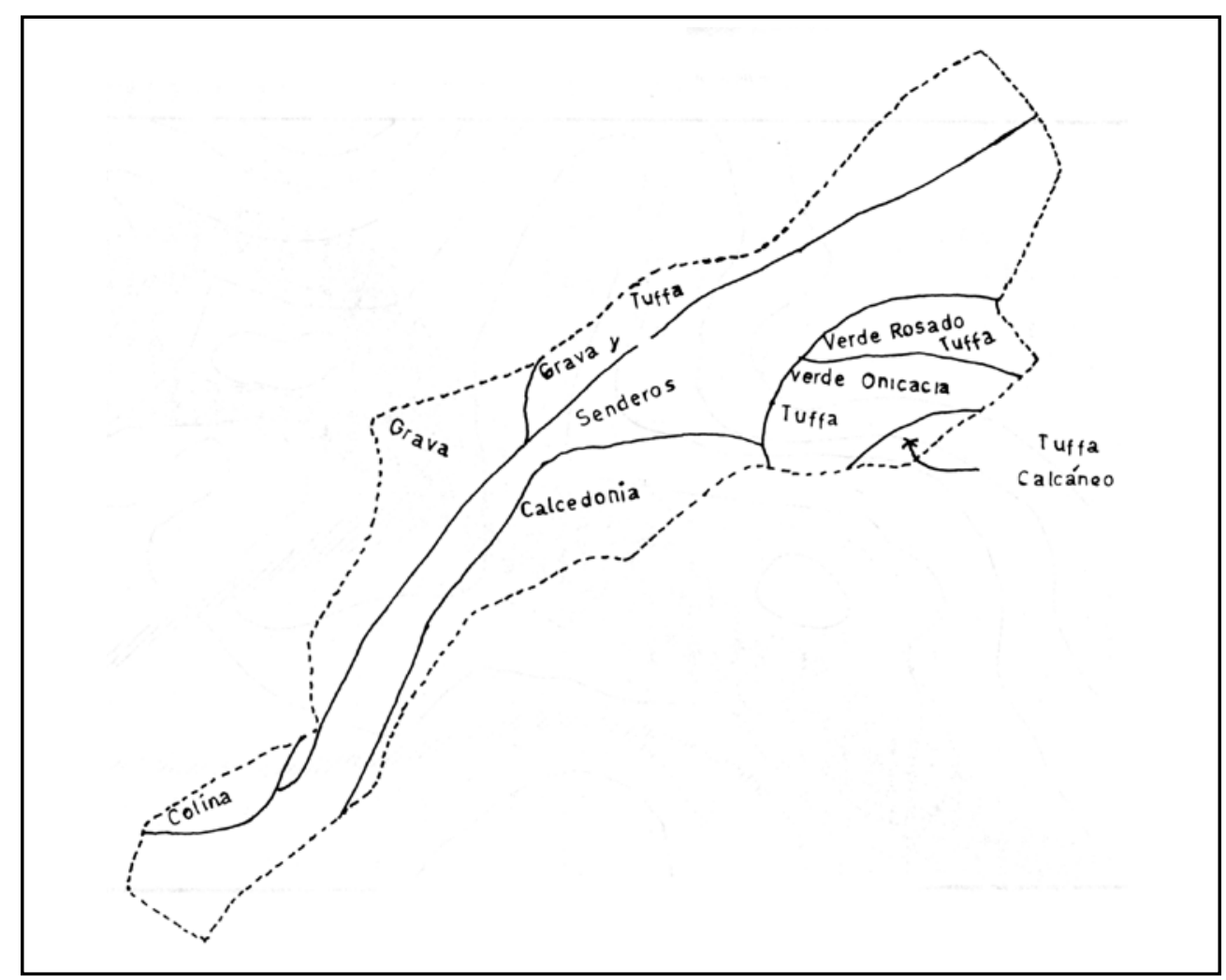

Figura 5. Diferentes cubiertas líticas del sitio RAnL-85, del llamado Complejo Chuqui.

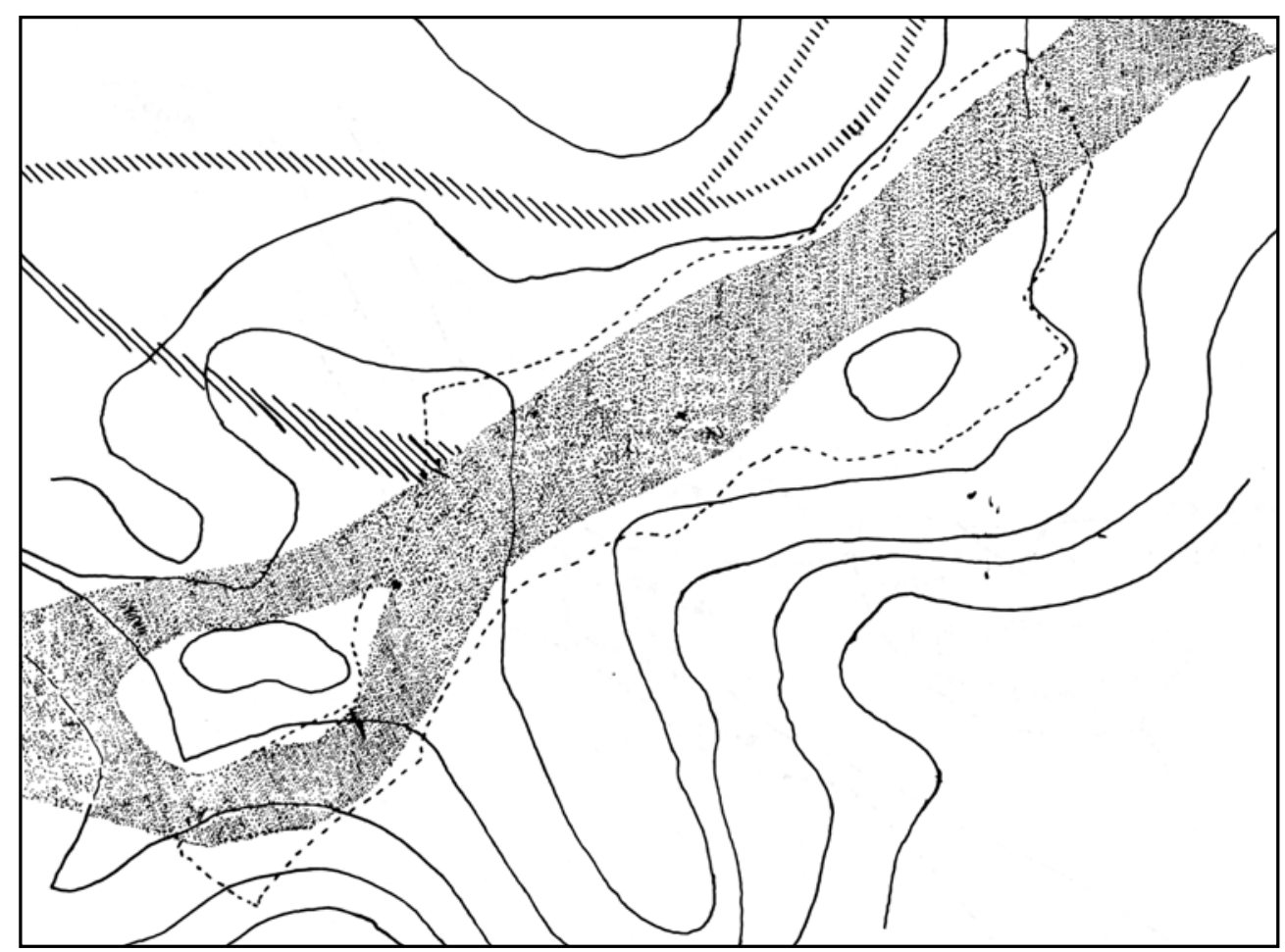

Figura 6. Senderos y caminos que cruzan el sitio RAnL-85. 
otros lugares la naturaleza de la superficie del terreno forzaba a los vehículos a rodear los obstáculos pasando sólo los animales de carga. Tal separación es muy visible en el sitio 6 (Figura 7). Estos senderos se usan poco hoy día, excepto por viajeros que van desde Calama a la fiesta anual de Ayquina. En este tiempo unas dos docenas de personas al día transitan estos senderos pasando a lo largo de los sitios Chuqui para lograr un atajo hacia Chiu Chiu. Otra evidencia del uso postconquista de estos senderos es la gran cantidad de herraduras de caballo y burro, aparejos de carros, esqueletos de burros y caballos, ocasional cerámica del Periodo Colonial, y numerosas botellas y tarros oxidados; todo esto se encuentra a lo largo de los senderos, y en ninguna otra parte. Similarmente, en varios lugares donde pasan los senderos que bordean el salar de Talabre se encuentran evidencias de estructuras postconquista. Los senderos se usaron probablemente para comercio general y para abastecer a los exploradores durante la era del salitre. Bowman (1924) hace notar que el ganado de Argentina a veces era llevado a Chiu Chiu y más al norte cuando no se ofrecía buen precio en San Pedro de Atacama. La mejor de las dos rutas por la que se pudo hacer tal travesía es de San Pedro hacia La Teca y hacia Calama, y luego a Chiu Chiu a través del salar de Talabre. Esta ruta cruza todos los sitios Chuqui en el salar.

Debido al intenso tráfico por los sitios y a la falta de separación entre el material Chuqui y los artefactos definitivamente de periodos más tardíos, creo no poder aceptar que estos sitios sean considerados como sitios-tipos para un complejo cultural. Más aún, creo que los supuestos artefactos Chuqui se explican más por medios naturales o por referencia ocasional a complejos ya establecidos, que por una postulación de un complejo industrial separado. En suma, mis datos indican que la formulación del Complejo Chuqui fue hecha prematuramente. Para formular un complejo cultural se debe tener la firme evidencia de que los componentes de ese complejo se una unidad y que los supuestos artefactos son por todos los medios obra del hombre. El Complejo Chuqui, tal como está en este momento, no cumple ninguno de los dos requisitos.

Las dificultades relacionadas con el primero de los requisitos en los sitios Chuqui ya ha sido discutida. Ahora trataré de demostrar que los supuestos artefactos Chuqui son a menudo producidos en forma natural. También mostraré que existen varios medios por los que se puede lograr tal desbaste natural. Puede encontrarse mucha información relativa a este tema en la amplia literatura sobre los controvertidos eolitos, en las primeras décadas del presente siglo. En tales debates se estipuló que muchos de los litos rudamente trabajados de varias localidades de Europa occidental eran el resultado de una cultura humana "prepaleolítica". Muchos argumentos surgieron tanto a favor como en contra de la naturaleza cultural de este material, y es buena idea revisar algunos de éstos. Entre los argumentos a favor de la naturaleza cultural de los eolitos estaban la similitud de forma y tipo de desbaste, y el fracaso de algunos investigadores que trataban de reproducir los supuestos artefactos mediante experimentos que duplicaran la acción de la naturaleza. Ambos argumentos fueron rechazados varias veces por otros investigadores que habían realizado una serie de interesantes experimentos (p.e., Warren 1905, 1914; Haward 1913).

\section{Warren (1914: 427) nota que:}

"Es particularmente notorio que los efectos obtenidos (por movimiento bajo presión en pedernal tabular o plano-convexo) van en conformidad con una serie de 'tipos' bien definidos. De estos 'tipos' la muesca o seudorraspador cóncavo es el punto central y dominante sobre el resto. En una dirección, la muesca se vuelve poco profunda y pasa a través del borde recto hacia el curvo llegando a ser un seudorraspador, o llega a lograr un desbaste marginal indefinido. Por otro lado, la muesca se encuentra tanto doble como doble reversa (el seudotaladro), o se presenta con combinación con otro tipo de desbaste en los bordes".

Más abajo, en la misma página, escribe:

"Al realizar experimentos bajo presión, año tras año, uno encuentra que el mismo grupo de formas se repiten indefinidamente en los resultados obtenidos, y que estos resultados no se pueden distinguir de las formas eolíticas".

Aunque las diferencias del tipo de materia prima hace difícil las comparaciones, es interesante notar que las mismas formas citadas por Warren son las predominantes en el material de Chuqui. La Figura 8 muestra algunos de los eolitos de los experimentos de Warren, y en la Figura 9 se reproducen algunas ilustraciones de Lanning sobre especímenes Chuqui. Aunque esta comparación no puede probar la 


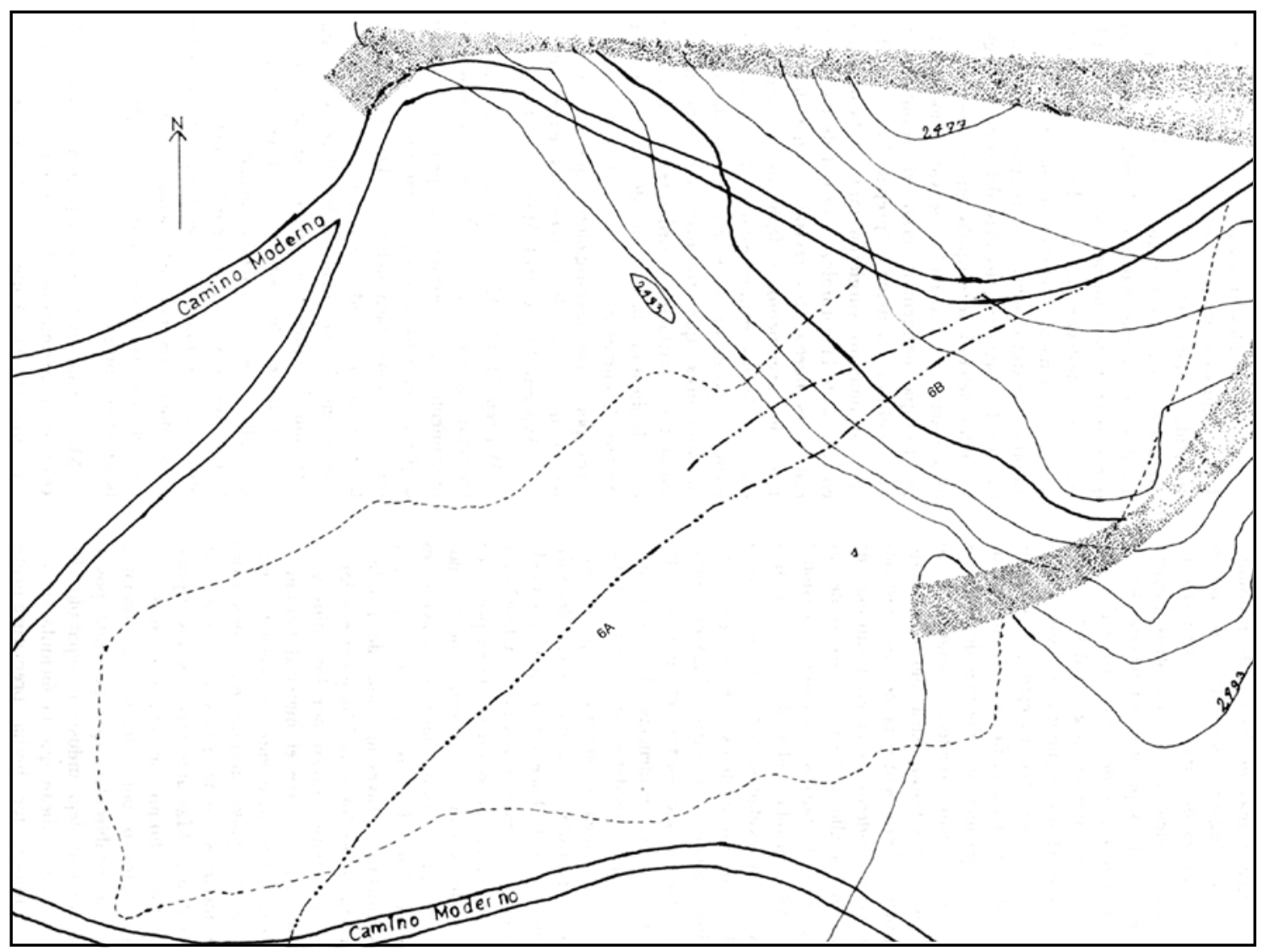

scala 1:1000

Figura 7. Distribución de caminos y senderos (RAnL-6).

naturaleza no cultural del Complejo Chuqui, por lo menos muestra la posibilidad de que los especímenes Chuqui sean naturales. De igual forma, ambos experimentos y el hecho que el material de Chuqui se parezca tanto a los artefactos que hoy día hacen los aborígenes australianos, indica que los especímenes Chuqui pudieron haber sido hechos por el hombre. Estas comparaciones sólo sirven para indicar que debe usarse mucha cautela al considerar el material de Chuqui. Lanning conoce esto y deja constancia (1970: 94), que la naturaleza ha desempeñado un gran papel en los sitios Chuqui. Mis estudios indican que la totalidad del complejo puede estar compuesto de material desbastado naturalmente.

Los tipos de fuerzas que Warren descubrió que producían formas más similares a los especímenes Chuqui fueron las que él llamó "golpe certero" y "movimiento diferencial bajo presión". Desde la formación de cada sitio Chuqui hasta la actualidad han existido muchos medios naturales que pudieron ejercer estas fuerzas. El primero de estos agentes naturales es el paso de los animales a través de los sitios. Si un solo golpe de taco de Warren pudo producir el desbaste que se muestra en la Figura 8, la pisada de una llama cargada o la herradura de un burro seguramente pudo tener un efecto similar en algunos de los materiales de estos sitios. Más aún, el peso de un animal cargado está distribuido en cuatro pequeñas áreas mientras camina, y fácilmente puede ejercer la presión suficiente para causar un desbaste adicional. Por lo menos algún desbaste fue hecho de esta manera, lo que está indicado en las marcas de óxido que presenta la plataforma de percusión de muchas piezas líticas de los sitios Chuqui. La única forma de contacto con hierro que pude ubicar en las cercanías de los sitios fueron las ruedas de carruajes y herraduras. Las herraduras están hechas de hierro dulce o maleable, y se ha 

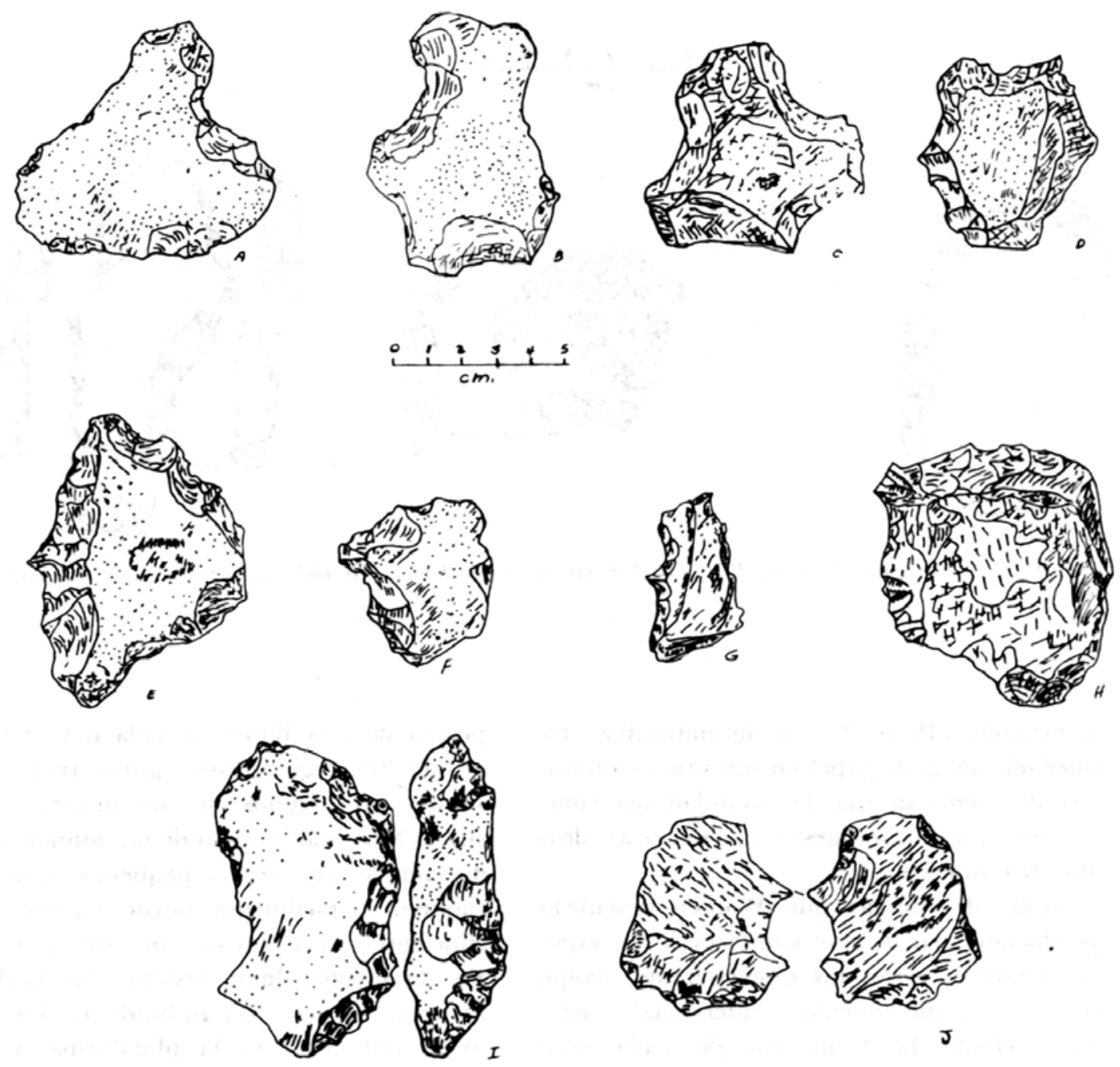

Figura 8. Fortuitous pressure flaking (Warren 1905: Plate XXVI). a, g, i, j: Immitation eoliths made at meeting of the Anthropological Institute on 19 December 1905. Each notch was made with a singe "stamp with the heel" in examples $\mathbf{g}$ and $\mathbf{j}$ although Warren states that both notches on $\mathbf{g}$ coald have been made with a single blow if the pressure had been against two pebles instead of one. b, f, m: examples of "crat-wheel" floking on new roads. 

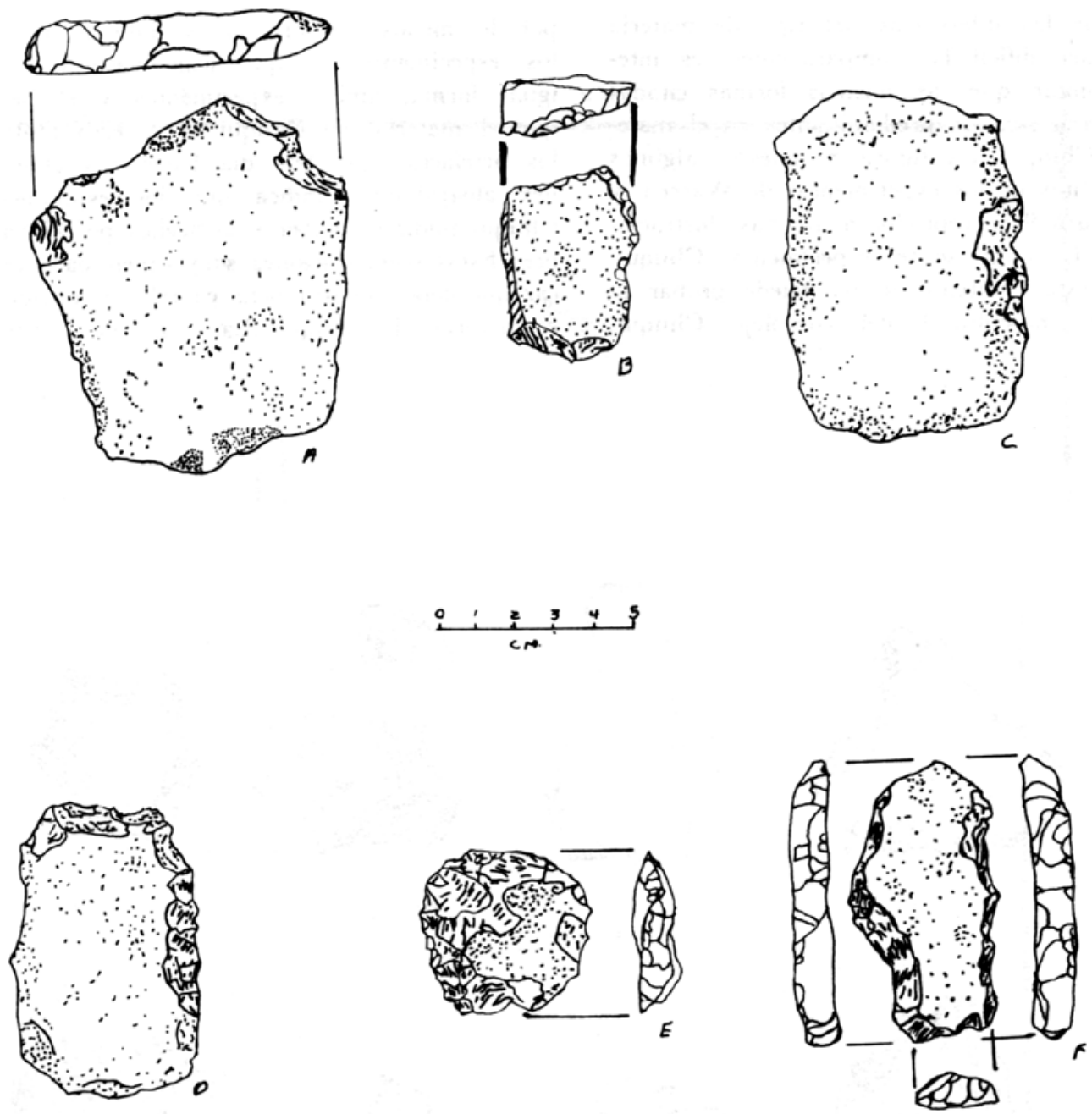

Figura 9. Artefactos Chuqui tempranos (Lanning 1970: 93). a, f: reversed retouch pieces; b, d, e: retouched tools; c: notched piece.

visto que las pulidas dejan manchas de hierro sobre las rocas sólo con un ligero golpe.

Una segunda causa posible de desbaste natural en los sitios Chuqui es el paso de carros a través de ellos. Warren ilustra varios ejemplos de eolitos hechos por tal proceso (Figura 8).

De este modo, Sellers escribe en 1885 :

"Un carro pesado, cargado con toneles de tabaco, guiado por un yugo de cinco o seis bueyes, pasó sobre un camino con grava recién puesta, haciendo un sonido agudo, golpeante y crujiente. Al examinar las huellas de las ruedas me sorprendía al encontrar la pequeña impresión que la rueda de hierro había hecho en la superficie de las piedras. Estas habían sido comprimidas hacia los lados de las ruedas del carro, dejando un pequeño surco; las piedras que quedaron comprimidas bajo las ruedas se fragmentaron тиy poco, no lo suficiente a juzgar por el sonido agudo que hicieron las ruedas al pasar sobre ellas. Al examinar el efecto del paso de las ruedas sobre el viejo camino, con una profundidad de 6 pulgadas, encontré que la mayoría de las piedras bajo la capa superficial estaban partidas, algunas astilladas, las fracturas iban en varias direcciones, algunas entrecruzándose. Este efecto, alcanzó una 
extensión de más o menos tres veces el ancho de la rueda. Muchas de las fracturas frescas presentaron formas y apariencia de verdaderos núcleos, y podrían haber sido confundidos con el trabajo del hombre. Fue una bonita ilustración del efecto de presión en pequeños puntos de contacto" (p. 891).

Todavía un tercer medio posible de lasqueo natural en los sitios Chuqui lo constituye el movimiento de la costra salina mientras se expande a raíz de los cambios de temperatura diaria. Este movimiento es suficiente para causar una considerable cantidad de quebrajamiento sonoro durante varias horas cada día. Puede argumentarse que este movimiento no disipa suficiente energía como para quebrar piedras; pero de hecho sólo una pequeña cantidad de presión es necesaria para causar pequeños desbastes en los bordes de dos rocas que chocan entre sí. La Tabla 2 reproduce los resultados de algunos de los experimentos de lasqueo de pedernal hechos por Warren.

Las presiones menores son muy fáciles de obtener. Por ejemplo, si la costra salina ejerce una fuerza de $35 \mathrm{gr} \mathrm{x} \mathrm{cm}^{2}$ en una roca que tiene una superficie de $10 \mathrm{~cm}^{2}$ enterrada en forma perpendicular a la dirección de esa fuerza, la presión ejercida en una esquina de la roca que esté presionando un objeto inmóvil en la misma dirección, sería de un mínimo de $350 \mathrm{gr}$ y fácilmente podría ser 10 veces mayor. Esto depende de varios factores, como el largo de la porción sin apoyo de la roca móvil. También influyen muchos otros factores, pero este ejemplo puede servir para ilustrar mi punto de vista.

La objeción que se puede hacer a cualquiera de las posibles causas de desbaste natural que he mencionado para los sitios Chuqui, es que, aunque sean factores que contribuyen a ello, no pueden explicar

\begin{tabular}{|c|c|}
\hline $\begin{array}{c}\text { Total de presión estimada } \\
(\mathbf{k g})\end{array}$ & $\begin{array}{c}\text { Area de lasqueo } \\
\left(\mathbf{c m}^{\mathbf{2}}\right)\end{array}$ \\
\hline 139.0 & 8.0 \\
\hline 101.0 & 16.0 \\
\hline 89.5 & 4.0 \\
\hline 57.3 & 2.75 \\
\hline 43.5 & 2.0 \\
\hline 21.2 & 1.0 \\
\hline 8.0 & 0.2 \\
\hline 3.5 & 0.05 \\
\hline
\end{tabular}

Tabla 2. Area de lasqueo obtenido por presión. Tomado de Warren (1914: 440).

el gran número de piezas talladas existentes. Este argumento fácilmente se descarta presentando la evidencia en perspectiva. Se han realizado cálculos actuales sobre $500 \mathrm{~m}$ en el sitio 73 , obteniendo como resultado que existen 37 litos de por lo menos $2 \mathrm{~cm}$ de largo por $\mathrm{m}^{2}$. Esto significa que hay cerca de 145.000 de tales litos en la superficie del sitio. Como sabemos que existió un intenso tráfico a través del sitio por lo menos durante 2000 años, es obvia la probabilidad de que un gran número de tales litos fueran desbastados naturalmente, aun si las posibilidades para tal desbaste fueran pocas en alguna época.

En conclusión, por lo tanto, sobre las bases de mi información, no puedo aceptar la existencia del Complejo Chuqui. Puede aparecer en el futuro alguna otra información que podría hacerme reconsiderar mi posición sobre este postulado complejo, pero por ahora tal información no parece que pudiera provenir del salar de Talabre.

Septiembre de 1970 


\section{REFERENCIAS CITADAS}

BOWMAN, I., 1924. Desert trails of the Atacama. American Geographical Society, Nueva York.

HAWARD, F. N. 1913. The problem of eoliths. Proceedings of the Prehistoric Society of East Anglia I: 347-359.

LANNING, E. P. 1969 Ms. Middle Loa Region, Norte Chile.

1970. Pleistocene man in South America. World Archaeology 1 (1): 90-111.

1973. Industria de buriles en el Pleistoceno de los Andes. Estudios Atacameños 1: 21-38.
SEEBERGER, H., 1966. Mapa regional de la Asociación de Pesca y Caza de Chuquicamata, Chuquicamata.

SELLERS. G. E., 1885. Observations on stone chipping, Annual Report of the Smithsonian Institution, part I: 871-891.

WARREN, S. H., 1905. On the origin of 'eolithic' flints by natural causes, especially by the foundering of drifts. Journal of the Royal Anthropological Institute XXXV: 337-365.

- 1914. The experimental investigation of flint fracture and its application to the problem of human implements. Journal of the Royal Anthropological Institute XLIV: 412-450. 